\title{
Antibiotic Prescribing Pattern in Primary Care Practice in Federal Territory Kuala Lumpur and Putrajaya, Malaysia
}

\author{
Audrey Huili Lim ${ }^{1}$, Wong Shieh Teng ${ }^{2}$, Thian Soon Yew ${ }^{3}$, Tew Wan Yin ${ }^{4}$, ChiewSiowYeh ${ }^{5}$, Lee \\ Xianhui $^{6}$, Hor Yee Yee ${ }^{7}$ \\ ${ }^{1}$ Centre for Clinical Outcomes Research, Institute for Clinical Research, National Institutes of Health, Ministry of \\ Health Malaysia \\ ${ }^{2}$ Hospital Rehabilitasi Cheras, Federal Territory Kuala Lumpur and Putrajaya, Malaysia \\ ${ }^{3}$ Pharmaceutical Services Division, Federal Territory Kuala Lumpur and Putrajaya, Malaysia \\ ${ }^{4}$ SetapakHeatlh Clinic, Federal Territory Kuala Lumpur and Putrajaya, Malaysia \\ ${ }^{5}$ Hospital Tengku Ampuan Afzan, Pahang, Malaysia \\ ${ }^{6}$ Cheras District Health Office, Federal Territory Kuala Lumpur and Putrajaya, Malaysia \\ ${ }^{7}$ Kuala Lumpur Heatlh Clinic, Federal Territory Kuala Lumpur and Putrajaya, Malaysia \\ ${ }^{\star}$ Correspondence E-mail : audreylim@moh.gov.my
}

\begin{abstract}
Introduction: The emerging of antibiotic resistance has become a challenge to global health and there is a strong association between antibiotic consumption and incidence of resistance. One of the tools to monitor and identify antibiotic prescribing pattern is Point Prevalence Survey (PPS).

Objectives: To determine the pattern of antibiotic prescribing in Primary Health Clinics (PHC) in Federal Territory Kuala Lumpur and Putrajaya (FTKLP). Methods: A cross-sectional study was conducted at 17 PHCs in FTKLP using universal sampling. Data from prescriptions received were recorded in PPS-PC data collection form. The compliance of the antibiotics prescribed were determined via cross-referencing with the Malaysian National Antibiotic Guideline (NAG) 2014 and/or Clinical Pathway for Antimicrobial Stewardship Program in PHCs (CP) 2019. Results: A total of 338 prescriptions with antibiotics were received and the prescribing rate of antibiotics at the PHCs in FTKLP 2019 was 5.94\%.Only 128 (37.9\%) prescriptions with antibiotics prescribed were compliant with either the NAG or the CP while $33(9.8 \%)$ prescriptions were found non-compliant with either guideline. Compliance of the remaining 177 prescriptions could not be determined due to non-specific diagnoses. The most commonly prescribed drug class was penicillin $(n=198,58.4 \%)$, followed by cephalosporins $(n=80,23.6 \%)$ and macrolides $(n=41,12 \%)$. Conclusion: This PPS study showed a low compliance of antibiotic prescribing to guidelines compared to recent studies and indicate the need for further action to be taken in order to improve antimicrobial prescribing in PHCs.
\end{abstract}

Keywords: Point prevalence survey, antibiotic, primary care

\section{Introduction}

Antibiotic resistance has become a challenge to global health (Dellit et al., 2007) leading to the World Health Organization developing a priority pathogens list in 2017 to ensure new antibiotics development are in-line with urgent public health needs (Beyer, 2020). However, recent reports showed that there are too few new antibiotics in development and more interventions are needed (Beyer, 2020). The emergence of antibiotic resistance in bacteria 
is directly linked to selective pressure exerted by inappropriate and overuse of antibiotics. Studies have shown that patients who have antibiotic resistance would have poorer clinical outcomes (Arason et al., 2006; Hiramatsu et al., 1997; Russell et al., 1998; Snow et al. 2001; Tenover, 2006). Antibiotic resistance is not only costly to national economies, but the impact on their health systems is significant as it affects productivity of patients or their caretakers through prolonged hospital stays and the need for more expensive and intensive care (Beyer, 2020).

A systematic review of low- and middleincome countries (LMICs) showed an antibiotic prescribing prevalence of $52 \%$, with a subset of studies reporting a high proportion of inappropriate use. Shively, et al. found that no antibiotic was indicated in $49.7 \%$ of cases in primary care clinics within a veteran affairs health care system (Shively et al. 2018) while a cross-sectional study of antibiotics prescribed for acute sinusitis cases in primary care showed that only half of the cases met antibiotic prescribing criteria (Truitt et al. 2020).

Many institutions conduct Antimicrobial Stewardship Programs (ASPs) to optimize antimicrobial therapy, reduce treatment-related cost, improve clinical outcomes and safety, and to reduce or stabilize antimicrobial resistance (Owens, 2008). The formal guidelines for ASPs were developed in 2007 by the Infection Diseases Society of America (IDSA) and the Society of Healthcare Epidemiology of America (SHEA) (Dellit et al., 2007). Strategies for changing antimicrobial prescribing behaviour include education of prescribers regarding proper antimicrobial usage, creation of an antimicrobial formulary with restricted prescribing of targeted agents, and review of antimicrobial prescribing with feedback to prescribers. Antibiotic rotation strategies were also used to control the prescribing process by scheduled changes of antimicrobial classes used for empirical therapy (Drew, 2009).

One of the tools to monitor and identify antibiotic prescribing pattern in a single assessment is Point Prevalence Survey (PPS) which is particularly useful in a limited time and resources setting for continuous surveillance (Zarb \& Goossens, 2011). Survey on antibiotic prescribing in health clinic encourages standardization and facilitates comparisons of antibiotic use over time and between clinics or districts. PPS with the aim of collecting baseline information on the use of antibiotics in health clinics is in accordance to WHO Methodology for Point Prevalence Survey on Antibiotic Use in Hospitals (World Health Organisation, 2019b). Furthermore, antimicrobial stewardship program effectiveness and trend monitoring can be done via repeated PPS within the same facility (Zarb \& Goossens, 2011).With this insight, the inappropriate pattern of antibiotic use can be improved by the promotion of better antimicrobial prescribing such as guidelines, improved clinical practice and antibiotic stewardship.

Aims

The objectives of this study are to determine the pattern of antibiotic prescribing, the prescribing rate of antibiotic to the total number of prescriptions, to identify the antibiotic classes prescribed, to identify the top antibiotic usage, to identify total antibiotic prescriptions according to prescriber category in $\mathrm{MOH}$ Formulary and to determine the appropriate use of antibiotic according to National Antibiotic Guideline (NAG) 2014 (Ministry of Health Malaysia, 2014)and Clinical Pathway for Antimicrobial Stewardship Program in Primary Health Clinic (CP) 2019(Ministry of Health Malaysia, 2019a).

\section{Materials and Method}

This study was a cross-sectional study conducted at 17 health clinics in Kuala Lumpur and Putrajaya using universal sampling.

\section{Inclusion and exclusion criteria}

All prescriptions from all age group during office hours and extended hours with oral or injectable antibiotics received on 9 April 2019 were taken into account. Prescriptions from other healthcare facilities, "Sistem Pendispensan Ubat Bersepadu" (SPUB) prescriptions, refill prescriptions and dental prescriptions were excluded. 


\section{Data Extraction}

The information from the collected prescription was tabulated in the data collection form (Appendix B). A total of 338 sample size was collected and the concordance of the antibiotics prescribed according to the Malaysia NAG 2014 and/or CP 2019 were determined via cross-referencing.

\section{Study population}

All patients who seek treatment at 17 health clinics included in this study.

\section{Data Analyses}

The data collected was analyzed using Microsoft Excel Spreadsheet Software version 2016. All the study objectives in this study will be analyzed using descriptive statistic. Diagnosis extracted from the prescriptions were coded as per Appendix A.

The CP 2019 was used as reference for Point Prevalence Survey (PPS) 2019 where information of differential diagnosis until selection of antibiotics are layout in this clinical pathway. The choice of antibiotics is in accordance to the NAG 2014(Ministry of Health Malaysia, 2014). The antibiotics of choice are segregated into the category of prescribers that are authorized to initiate the prescription for the drug in this Ministry of Health Drug formulary. The five categories are as listed:

$A^{*}=$ Consultant $/$ Specialist for specific indication only

$\mathrm{A}=$ Consultant $/$ Specialist

$\mathrm{A} / \mathrm{KK}=$ Consultant $/$ Specialist $/$ Family

Physicians Specialist

$B=$ Medical Officer

C $=$ Paramedical Staff

$\mathrm{C}+=$ Paramedical Staff doing midwifery

\section{Ethical Approval}

This study was reviewed and approved by the Medical Research and Ethics Committee of the Ministry of Health Malaysia vide ref number KKM/NIHSEC/P19-1263(5) dated 17 July 2019.

\section{Results}

The Point Prevalence Survey was conducted in 17 health clinics in FTKLP which involved type 1 facilities $(n=1)$, type 2 facilities $(n=4)$, type 3 facilities $(n=6)$, type 4 facilities $(n=2)$ and type 5 facilities $(n=4)$. A total of 8389 patients visited the 17 health clinics in FTKLP but only 5693 patients received prescriptions. Antibiotics were prescribed to 338 patients, of which 178 was female (53\%) and 160 was male $(47 \%)$, resulting in a prescribing rate of antibiotics of $5.94 \%$. Most of the patients were from the 19 - 39 age group, $n=144(42.6 \%)$, followed by $0-12$ years $(n=76 ; 22.9 \%), 40-59$ years $(n=55 ; 16.3 \%), \geq 60$ years old $(n=46$; $13.6 \%)$ and $3-18$ years $(n=17 ; 5.0 \%)$ (Table 1$)$.

A total of seven antibiotic classes were prescribed i.e. penicillins, cephalosporins, macrolides, nitroimidazoles, tetracyclines, sulfonamides, and others (Table 2). The most commonly prescribed antibiotic class was penicillins ( $n=198)$, followed by cephalosporins $(n=80)$ and macrolides $(n=41)$. These three classes comprised of $94.4 \%$ of antibiotic prescriptions on the day of the study. Amoxycillin capsules ( $n=92)$ and syrups $(\mathrm{N}=45)$ were the most commonly prescribed penicillins while cephalexin capsules $(n=70)$ and syrups $(n=6)$ were the most commonly prescribed cephalosporins.

Pharmacists intervened on $62(18.3 \%)$ of the 338 antibiotic prescriptions. The most frequent causes for intervention by pharmacists were inappropriate duration of antibiotics prescribed $(n=31 ; 50.0 \%)$, frequency $(n=6 ; 9.7 \%)$ and diagnosis $(n=2 ; 3.2 \%)$. Only 33 prescriptions were compliant to both NAG and CP, but 54 (16.0\%) prescriptions were compliant to NAG while $107(31.7 \%)$ prescriptions were compliant to CP (Table 3). There were 33 prescriptions $(8.7 \%)$ non-compliant to both $\mathrm{CP}$ and NAG, 140 (41.4\%) prescriptions noncompliant to $\mathrm{CP}$ but not NAG, while 50 (14.8\%) prescriptions non-compliant to CP but not NAG. There are 8 types of non-compliance to either NAG 2014 or CP 2019, namely drug; dose; frequency; duration; dose and frequency; frequency and duration; dose, frequency and duration; and regimen (Table 4). The most common form non-compliance to the NAG was wrong duration of antibiotics 
prescribed ( $n=73$ ), followed by wrong drug for specified diagnosis $(\mathrm{n}=35)$ and wrong frequency $(n=17)$. On the other hand, the most common form of non-compliance to $\mathrm{CP}$ was wrong drug for specified diagnosis $(n=17)$, followed by wrong duration of antibiotics prescribed $(n=10)$, and wrong frequency $(\mathrm{n}=6)$.

Antibiotics prescribed for urinary tract infections (UTI) were the most often to be found non-compliant to NAG and CP $(n=13)$ or
CP only $(n=15)$ while antibiotics prescribed for upper respiratory tract infections (URTI) were the most often to be found non-compliant to NAG only $(n=66)$ (Table 5). However, antibiotics prescribed for UTIs were also the most often to be found compliant to NAG \& CP $(n=11)$ and NAG only $(n=15)$. The appropriateness of 177 antibiotics prescribed could not be determined due to insufficient data $(n=89)$ or unavailability of stated diagnosis on the prescription in either or both guidelines $(n=88)$.

Table 1 Demographic data of patients that received antibiotics and baseline characteristics

\begin{tabular}{|c|c|c|}
\hline Characteristics & $\mathbf{n}$ & $(\%)$ \\
\hline \multicolumn{3}{|l|}{ Gender } \\
\hline Male & $160(47.3)$ & 47.3 \\
\hline Female & $178(52.7)$ & 52.7 \\
\hline \multicolumn{3}{|l|}{ Age Group } \\
\hline $0-12$ & $76(22.5)$ & 22.5 \\
\hline $13-18$ & $17(5.0)$ & 5.0 \\
\hline $19-39$ & $144(42.6)$ & 42.6 \\
\hline $40-59$ & $55(16.3)$ & 16.3 \\
\hline$>60$ & $46(13.6)$ & 13.6 \\
\hline \multicolumn{3}{|l|}{ Time of Antibiotic Prescribing } \\
\hline Office hour & $318(94.1)$ & 94.1 \\
\hline Non-office hour & $20(5.9)$ & 5.9 \\
\hline \multicolumn{3}{|l|}{ Antibiotic Dosage Forms Prescribed } \\
\hline Solid & $264(78.1)$ & 78.1 \\
\hline Liquid & $68(20.1)$ & 20.1 \\
\hline Injection & $6(1.8)$ & 1.8 \\
\hline \multicolumn{3}{|l|}{ Antibiotic Intervention by Pharmacist } \\
\hline Yes & $62(18.3)$ & 18.3 \\
\hline No & $276(81.7)$ & 81.7 \\
\hline \multicolumn{3}{|l|}{ Prescriber Category of Antibiotics } \\
\hline $\mathrm{A} / \mathrm{KK}$ & 8 & 2.4 \\
\hline B & 329 & 97.3 \\
\hline C & 1 & 0.3 \\
\hline \multicolumn{3}{|l|}{ Diagnosis } \\
\hline Upper Respiratory Tract Infection (URTI) & 121 & $35.80 \%$ \\
\hline Others & 77 & $22.78 \%$ \\
\hline Soft \& Skin Tissue Injury (SSTI) & 69 & $20.41 \%$ \\
\hline Urinary Tract Infection (UTI) & 41 & $12.13 \%$ \\
\hline Sexually Transmitted Infection (STI) & 19 & $5.62 \%$ \\
\hline Acute Gastroenteritis (AGE) & 6 & $1.78 \%$ \\
\hline No diagnosis & 5 & $1.48 \%$ \\
\hline
\end{tabular}


Table 2 Type of antibiotics prescribed by classes

\begin{tabular}{|c|c|c|c|}
\hline Type of Antibiotic & $\begin{array}{l}\text { Prescriber } \\
\text { Category }\end{array}$ & Number & Percentage \\
\hline Penicillins & & 198 & 58.4 \\
\hline Amoxicillin & B & 138 & 70.0 \\
\hline Cloxacillin & B & 54 & 27.0 \\
\hline Benzathine Penicillin & B & 4 & 2.0 \\
\hline Amoxicillin \& Clavulanate & $\mathrm{A} / \mathrm{KK}$ & 1 & 0.5 \\
\hline Phenoxymethyl Penicillin & $\mathrm{C}$ & 1 & 0.5 \\
\hline Cephalosporins & & 80 & 23.6 \\
\hline Cephalexin & B & 76 & 95.0 \\
\hline Cefuroxime & $\mathrm{A} / \mathrm{KK}$ & 2 & 2.5 \\
\hline Ceftriaxone & $\mathrm{A} / \mathrm{KK}$ & 2 & 2.5 \\
\hline Macrolides & & 41 & 12.0 \\
\hline Erythromycin Ethylsuccinate & B & 38 & 92.7 \\
\hline Azithromycin & $\mathrm{A} / \mathrm{KK}$ & 3 & 7.2 \\
\hline Nitroimidazoles & & 9 & 2.7 \\
\hline Metronidazole 200 mg Tablet & B & 9 & 2.7 \\
\hline Tetrcycline & & 5 & 1.5 \\
\hline Doxycycline 100 mg Capsule & B & 5 & 1.5 \\
\hline Sulfonamides & & 4 & 1.2 \\
\hline Sulphamethoxazole $400 \mathrm{mg} \&$ Trimethoprim $80 \mathrm{mg}$ Tablet & B & 4 & 1.2 \\
\hline Others & & 2 & 0.6 \\
\hline Nitrofurantoin 100 mg Tablet & B & 1 & 0.3 \\
\hline Dapsone 100 mg Tab & B & 1 & 0.3 \\
\hline
\end{tabular}

Table 3 Appropriateness of antibiotics prescribed

\begin{tabular}{lcc}
\hline & $\mathbf{n}$ & $\%$ \\
\hline Compliant to EITHER NAG or CP & $\mathbf{1 6 1}$ & $\mathbf{4 7 . 6}$ \\
$\quad$ NAG & 54 & 16.0 \\
$\quad$ CP & 107 & 31.7 \\
\hline Undetermined & $\mathbf{1 7 7}$ & $\mathbf{5 2 . 4}$ \\
\hline TOTAL & $\mathbf{3 3 8}$ & \\
\hline Non-compliant to EITHER NAG or CP & $\mathbf{1 9 0}$ & $\mathbf{5 6 . 2}$ \\
\hline
\end{tabular}

Table 4 Types of non-compliance

\begin{tabular}{lcc}
\hline Type of Non-compliance & NAG & CP \\
\hline Duration & 73 & 10 \\
\hline Drug & 35 & 17 \\
Frequency & 17 & 6 \\
Frequency \& Duration & 6 & 0 \\
Regimen & 6 & 8 \\
\hline Dose & 2 & 6 \\
Dose \& Frequency & 1 & 2 \\
Dose, Frequency \& Duration & 0 & 1 \\
\hline TOTAL & $\mathbf{1 4 0}$ & $\mathbf{5 0}$ \\
\hline
\end{tabular}


Int J Adv Life Sci Res. Volume 4(4)15-24

Table 5 Compliance to guidelines by diagnosis

\begin{tabular}{lclc}
\hline Compliant & $\mathbf{n}$ & Non Compliant & $\mathbf{n}$ \\
\hline National Antibiotic Guidelines Only & & National Antibiotic Guidelines Only & \\
Urinary Tract Infection & 15 & Upper Respiratory Tract Infection & 66 \\
Otitis Media & 8 & Skin \& Soft Tissue Infection & 27 \\
Sexually Transmitted Infection & 8 & Urinary Tract Infection & 23 \\
Skin \& Soft Tissue Infection & 6 & Others & 13 \\
Acute Sinusitis & 4 & Otitis Media & 5 \\
Gonorrhoea & 4 & Impetigo & 3 \\
Impetigo & 3 & Pneumonia & 3 \\
Pneumonia & 2 & & \\
Upper Respiratory Tract Infection & 2 & & \\
Acne & 2 & & 19 \\
& & & 15 \\
Clinical Pathways Only & & Clinical Pathways Only & \\
Upper Respiratory Tract Infection & 37 & Skin \& Soft Tissue Infection \\
Skin \& Soft Tissue Infection & 25 & Urinary Tract Infection & 5 \\
Urinary Tract Infection & 24 & Acute Gastroenteritis / Diarrhoea \\
Otitis Media & 10 & Others \\
Acute Sinusitis & 4 & Pneumonia \\
Impetigo & 3 & Impetigo \\
Gonorrhoea & 2 & & 4 \\
Pneumonia & 2 & & 4 \\
\hline
\end{tabular}

\section{Discussion}

\section{Summary}

This study evaluated the antibiotic prescribing pattern in FTKLP. Although the prescribing rate of $5.94 \%$ found in this study is higher than the national average of $4.1 \%$ (Sajari, 2019), it is lower than the $6.8 \%$ prescribing rate of antibiotics from National Medical Care Statistics(NMCS) 2014(Ab Rahman, Teng, \& Sivasampu, 2016). This shows that there's has been an improvement in the rate of antibiotic prescribing, especially with the use of $\mathrm{CP}$. This is evidenced from a higher compliance rate to $\mathrm{CP}$ than to NAG as CP was published 5 years after NAG. Nevertheless, the antibiotic prescribing rate in FTKLP may be higher than the national average due to the demographic of patients in this urban area. Also, at the point of study being conducted, the National Antimicrobial Guidelines 2019 (NAG 2019) was not launched yet. NAG 2019 was launched on 26thSeptember 2019. It is expected the newer and updated NAG 2019 will encourage more judicious use of antibiotics.

$\mathrm{CP}$ was published and circulated approximately 4 months before this study was conducted, and as such, prescribers were more mindful of this as compared to NAG as it was the latest guideline at the point of study. Frequent sessions of Continuous Medical Education (CME) were conducted to introduce the $\mathrm{CP}$ to prescribers. Besides that, the practicality of dosing influences the likelihood of compliance to the guidelines. For example, the preferred antibiotic for treatment of pharyngitis according to NAG and $\mathrm{CP}$ is phenoxymethyl penicillin $500 \mathrm{mg}$ twice daily for 10 days while the alternative treatment according to NAG is amoxycillin $500 \mathrm{mg}$ twice or thrice daily for 10 days(Ministry of Health Malaysia, 2014). However, the alternative treatment according to $\mathrm{CP}$ is amoxycillin $500 \mathrm{mg}$ thrice daily for 5-10 days or erythromycin $800 \mathrm{mg}$ twice daily for $5-10$ days(Ministry of Health Malaysia, 2019a). Prescribers were more likely to deviate from 
NAG and comply to CP by prescribing amoxycillin or erythromycin for 5 days in this case as patients need not take a long course of antibiotics, hence, more likely to be compliant.

\section{Comparison with existing literature}

The prescribing rate of antibiotics for URTIs was $35.8 \%$ was lower than previous results of 46.2\% from NMCS 2014 but was still considerably higher than the corresponding rates in the Netherlands and Hong Kong which were $17 \%$ and $5 \%$, respectively. This is a cause for concern as URTI cases are primarily viral (Hong et al., 2004) (bacterial aetiology in unselected URTI cases was $2.4 \%$; pharyngitis was $14 \%$ ) and do not warrant the use of antibiotics.

However, the antibiotic prescribing rate in FTKLP was still low compared to the findings in Sudan $54.3 \% \%$, Western China $48.43 \%$, Bahrain 45.8, Uzbekistan 57\%, Nigeria 56\%, $45.9 \%$ in the African region, eastern Ethiopia $82.5 \%$ and in primary health care centres in the WHO African region $46.8 \%$ (Sajari, 2019). These studies investigated antibiotic prescribing patterns within a longer duration of time (10 days and 3 months respectively) while our study reviewed antibiotic prescribing for only one day which may not be representative of overall antibiotic prescribing in the population (Chem et al., 2018).

A national morbidity and treatment survey of primary care clinics in 2008 revealed antibiotic prescribing rates in public and private clinics were 13.7 and $30.0 \%$, respectively (Salleh, n.d.). The antibiotic prescribing rate in public primary care clinics in FTKLP may be considerably low, while the prescribing rate of private clinics are still a cause for concern which require further investigation.

Almost half $(47.6 \%)$ of prescriptions were compliant to either NAG or CP. This is comparable to a study in Kenya (Maina et al., 2020) which found a compliance rate of $53.6 \%$ but much lower than that in Belgium (76.6\%) (Vandael et al., 2020) and UK (70\%) (Aldeyab et al., 2011). Antibiotic over-prescribing has long been identified as a cause of antimicrobial resistance and should be rectified immediately.
Based on the WHO AWaRe classification, the prescribed antibiotics in the study mostly belonged to the "Access" list and more than $80 \%$ of these are from Penicillin group and cephalosporin first generation (MartínezGonzález, Di Gangi, \& Pichierri, 2020)which provide the best therapeutic value, while minimizing the resistance potential(Hsia et al., 2019). The WHO AWaRe classification (Access, Watch and Reserve) is intended to be used as an interactive tool for better support antibiotic monitoring and optimal use nevertheless reducing antimicrobial resistance (Hsia et al., 2019). The Access antibiotics usage in our study is higher than the proportion (60\%) recommended by WHO (Martínez-González et al., 2020).

Most of the antibiotics prescribed were from the $\mathrm{B}$ Category i.e. prescribed by medical officers, whereas the number of prescriptions with antibiotics from primary health care specialists (A/KK Category) were low.In addition, cephalosporins (e.g., cefuroxime \& ceftriaxone) and macrolides (e.g., azithromycin) are under "Watch" list (Sulis et al., 2020). These antibiotics are prescribed by primary care specialists, who are known locally as family medicine specialists (Shamsuddin, Akkawi, Zaidi, Ming, \& Manan, 2016). Hence, the utilization of these antibiotics would be better controlled to prevent inappropriate use and antibiotic resistance (Sulis et al., 2020). This finding is similar to a local study conducted in 2013 where less than $3 \%$ of the prescriptions were prescribed by primary health care specialists (Shamsuddin et al., 2016). The segregation of antibiotics according to the prescriber category is one of the ways to control and limit the use of more expensive and broader spectrum antibiotics.

Amoxicillin, Cephalexin and Cloxacillin are the commonly prescribed antibiotic in descending order. The results of the present study are comparable to those of a study conducted at local primary healthcare clinics in Klangdistrict (Shamsuddin et al., 2016).

As most primary healthcare cases are usually mild, most of the prescribing can be done by medical officers where selection of the agents is based on their costs and therapeutic 
effectiveness (Finley et al., 2018). In this study, upper respiratory tract infection (URTI) was the most frequently encountered infection diagnosed for patients receiving antibiotics. This corresponds to the data of National Medical Care Survey 2014 conducted by the Clinical Centre Malaysia that collected information from both public and private primary care clinics in Malaysia where URTI was the most frequent diagnosis in patients receiving antibiotic treatment (Sivasampu et al., 2016).

\section{Strengths and Limitations}

One of the limitations of this study was the use of the cross-sectional design which is limited to a particular point in time. Second, there were prescriptions without diagnosis written or specified and hence, cross-referencing could not be carried out. Third, prescribers may have been aware of the PPS date beforehand when it was supposed to be confidential. This may have distorted the study findings.

Implications for research and/or practice

Proper diagnosis according to International Classification of Diseases, Eleventh Revision

\section{References}

Ab Rahman, N., Teng, C. L., \& Sivasampu, S. (2016). Antibiotic prescribing in public and private practice: a cross-sectional study in primary care clinics in Malaysia. BMC Infect Dis, 16, 208. doi: 10.1186/s12879-016-1530-2

Aldeyab, M. A., Kearney, M. P., McElnay, J. C., Magee, F. A., Conlon, G., Gill, D., . . . Scott, M. G. (2011). A point prevalence survey of antibiotic prescriptions: benchmarking and patterns of use. $\mathrm{Br}$ $J$ Clin Pharmacol, 71(2), 293-296. doi: 10.1111/j.1365-2125.2010.03840.x

Arason, V. A., Sigurdsson, J. A., Erlendsdottir, H., Gudmundsson, S., \& Kristinsson, K. G. (2006). The role of antimicrobial use in the epidemiology of resistant pneumococci: A 10-year follow up. doi: 10.1089/mdr.2006.12.169

Beyer, P. P., S. (2020). Priority pathogens and the antibiotic pipeline: an update. Bulletin of the World Health Organization, 98(151), 149-228. doi: http://dx.doi.org/10.2471/BLT.20.251751

Chem, E. D., Anong, D. N., \& Akoachere, J. K. T. (2018). Prescribing patterns and associated factors of antibiotic prescription in primary health care facilities of Kumbo East and Kumbo West Health Districts, North West Cameroon. PLOS ONE, 13(3), e0193353. doi: 10.1371/journal.pone.0193353
(ICD-11) should be encouraged for better documentation of patient's wellbeing(World Health Organisation, 2019a). CMEs will need to be carried out on a regular basis to remind and educate prescribers on the guidelines and recommended clinical pathways.

\section{Conclusion}

The prescribing rate of antibiotics at the Primary Health Clinics in FTKLP 2019 was $5.94 \%$. This PPS study showed higher compliance of antibiotic prescribing to $\mathrm{CP}$ 2019 than NAG 2014. Antimicrobial stewardship activities should be continued to work on improving antimicrobial prescribing in primary health care. This is pivotal to promote effective, judicious and safe use of antibiotics.

\section{Acknowledgments}

We wish to thank the Director General of Health, Ministry of Health Malaysia for the permission to publish the findings.

\section{Conflicts of Interest}

The authors declare no conflict of interest.

Dellit, T. H., Owens, R. C., McGowan, J. E., Gerding, D. N., Weinstein, R. A., Burke, J. P., . . . Hooton, T. M. (2007). Infectious Diseases Society of America and the Society for Healthcare Epidemiology of America Guidelines for Developing an Institutional Program to Enhance Antimicrobial Stewardship. Clinical Infectious Diseases, 44(2), 159-177. doi: 10.1086/510393

Drew, R. H. (2009). Antimicrobial stewardship programs: how to start and steer a successful program. J Manag Care Pharm, 15(2 Suppl), S1823. doi: 10.18553/jmcp.2009.15.s2.18

Finley, C. R., Chan, D. S., Garrison, S., Korownyk, C., Kolber, M. R., Campbell, S., . . Allan, G. M. (2018). What are the most common conditions in primary care? Systematic review. Canadian family physician Medecin de famille canadien, 64(11), 832-840.

Hiramatsu, K., Hanaki, H., Ino, T., Yabuta, K., Oguri, T., \& Tenover, F. C. (1997). Methicillinresistant Staphylococcus aureus clinical strain with reduced vancomycin susceptibility. J Antimicrob Chemother, 40(1), 135-136. doi: 10.1093/jac/40.1.135

Hong, C.-Y., Lin, R. T., Tan, E. S., Chong, P.-N., Tan, Y. S., Lew, Y.-J., \& Loo, L.-H. (2004). Acute respiratory symptoms in adults in general practice. 
Family Practice, 21(3), 317-323. doi: 10.1093/fampra/cmh319

Hsia, Y., Lee, B. R., Versporten, A., Yang, Y., Bielicki, J., Jackson, C., . . . Sharland, M. (2019). Use of the WHO Access, Watch, and Reserve classification to define patterns of hospital antibiotic use (AWaRe): an analysis of paediatric survey data from 56 countries. Lancet Glob Health, 7(7), e861e871. doi: 10.1016/s2214-109x(19)30071-3

Maina, M., Mwaniki, P., Odira, E., Kiko, N., McKnight, J., Schultsz, C., . . . Tosas-Auguet, O. (2020). Antibiotic use in Kenyan public hospitals: Prevalence, appropriateness and link to guideline availability. International Journal of Infectious Diseases, 99, 10-18. doi: https://doi.org/10.1016/j.ijid.2020.07.084

Ministry of Health Malaysia (2014). National Antibiotic Guideline 2014. Petaling Jaya: Pharmaceutical Services Division.

Ministry of Health Malaysia (2019a). Clinical Pathway for Antimicrobial Stewardship Program in Primary Health Clinic 2019. Petaling Jaya: Pharmaceutical Services Division.

Ministry of Health Malaysia (2019b). National Antimicrobial Guideline 2019 Petaling Jaya: Pharmaceutical Services Programme.

Martínez-González, N. A., Di Gangi, S., \& Pichierri, G. (2020). Time Trends and Factors Associated with Antibiotic Prescribing in Swiss Primary Care (2008 to 2020). Antibiotics (Basel), 9(11). doi: 10.3390/antibiotics9110837

Organisation, W. H. (2019a). International Statistical Classification of Diseases and Related Health Problems (ICD). Retrieved 26 April 2021, 2021

Organisation, W. H. (2019b). WHO Methodology for Point Prevalence Survey on Antibiotic Use in Hospitals (pp. 102): World Health Organisation.

Owens, R. C., Jr. (2008). Antimicrobial stewardship: concepts and strategies in the 21st century. Diagn Microbiol Infect Dis, 61(1), 110-128. doi: 10.1016/j.diagmicrobio.2008.02.012

Russell, A. D., Tattawasart, U., Maillard, J.-Y., \& Furr, J. R. (1998). Possible Link between Bacterial Resistance and Use of Antibiotics and Biocides. Antimicrobial Agents and Chemotherapy, 42(8), 2151-2151. doi: 10.1128/aac.42.8.2151

Sajari, J. (2019). Antibiotic Point Prevalence Survey (PPS) in $\mathrm{MOH}$ Primary Care Clinics 2019. Paper presented at the National Antimicrobial Guideline 2019 Launch.

Salleh, N. (unpublished data). Ministry of Health, Malaysia. Kuala Lumpur.
Shamsuddin, S., Akkawi, M. E., Zaidi, S. T., Ming, L. C., \& Manan, M. M. (2016). Antimicrobial drug use in primary healthcare clinics: a retrospective evaluation. Int $J$ Infect Dis, 52, 16-22. doi: 10.1016/j.ijid.2016.09.013

Shively, N. R., Buehrle, D. J., Clancy, C. J., \& Decker, B. K. (2018). Prevalence of Inappropriate Antibiotic Prescribing in Primary Care Clinics within a Veterans Affairs Health Care System. Antimicrobial Agents and Chemotherapy, 62(8), e00337-00318. doi: 10.1128/AAC.00337-18

Sivasampu, S., Wahab, Y. F., Ong, S. M., Ismail, S. A., Goh, P. P., \& Jeyaindran, S. (2016). National Medical Care Statistics (NMCS) 2014 National Healthcare Statistics Initiative: National Clinical Research Centre.

Snow, V., Mottur-Pilson, C., \& Gonzales, R. (2001). Principles of appropriate antibiotic use for treatment of nonspecific upper respiratory tract infections in adults. Ann Intern Med, 134(6), 487-489. doi: 10.7326/0003-4819-134-6-200103200-00014

Sulis, G., Daniels, B., Kwan, A., Gandra, S., Daftary, A., Das, J., \& Pai, M. (2020). Antibiotic overuse in the primary health care setting: a secondary data analysis of standardised patient studies from India, China and Kenya. BMJ Global Health, 5(9), e003393. doi: 10.1136/bmjgh-2020003393

Tenover, F. C. (2006). Mechanisms of antimicrobial resistance in bacteria. Am J Med, 119(6 Suppl 1), S3-10; discussion S62-70. doi: 10.1016/j.amjmed.2006.03.011

Truitt, K. N., Brown, T., Lee, J. Y., \& Linder, J. A. (2020). Appropriateness of Antibiotic Prescribing for Acute Sinusitis in Primary Care: A Cross-sectional Study. Clinical Infectious Diseases. doi: 10.1093/cid/ciaa736

Vandael, E., Latour, K., Goossens, H., Magerman, K., Drapier, N., Catry, B., . . . the Belgian Point Prevalence Survey Study, G. (2020). Point prevalence survey of antimicrobial use and healthcare-associated infections in Belgian acute care hospitals: results of the Global-PPS and ECDC-PPS 2017. Antimicrobial Resistance \& Infection Control, 9(1), 13. doi: 10.1186/s13756019-0663-7

Zarb, P., \& Goossens, H. (2011). European Surveillance of Antimicrobial Consumption (ESAC): value of a point-prevalence survey of antimicrobial use across Europe. Drugs, 71(6), 745-755. doi: 10.2165/11591180-000000000-00000 
Int J Adv Life Sci Res. Volume 4(4)15-24

\section{Appendix A: List of Diagnosis Coding}

\begin{tabular}{|l|l|l|}
\hline Code & Diagnosis & Descriptions \\
\hline $\mathbf{1}$ & $\begin{array}{l}\text { Upper Respiratory } \\
\text { Tract Infection } \\
\text { (URTI) }\end{array}$ & $\begin{array}{l}\text { Infection which involves the upper respiratory tract including nose, sinuses, } \\
\text { pharynxorlarynx } \\
\text { Eg: Sore throat, Flu/RunnyNose, Common Cold, Cough, Pharyngitis, Tonsilitis, } \\
\text { Laryngitis, Diphteria, Acute Bacterial Rhinosinusitis, Acute Epiglottitis }\end{array}$ \\
\hline $\mathbf{2}$ & $\begin{array}{l}\text { Soft \& Skin Tissue } \\
\text { Injury (SSTI) }\end{array}$ & $\begin{array}{l}\text { Infections of skin, subcutaneous tissue, fascia and muscle } \\
\text { Eg: Impetigo, Erysipelas, Cellulitis, Lymphadenitis, Diabetic Foot Infections } \\
\text { (Myonecrosis, Gas Gangrene, Necrotizing Fascitis, Yaws), Boils, Burns, Cuts, } \\
\text { Bites, Trauma (open wound), Acne, Conjuctivitis, Stye, Chalazion }\end{array}$ \\
\hline $\mathbf{3}$ & $\begin{array}{l}\text { Urinary Tract } \\
\text { Infection (UTI) }\end{array}$ & $\begin{array}{l}\text { Infections that affects the bladder, the kidneys and the tubes connecting them. } \\
\text { Eg: Acute Uncomplicated Cystitis, Acute Cystitis in Pregnancy, Acute } \\
\text { Uncomplicated Pyelonephritis, Bacteriuria in pregnancy, Asymptomatic } \\
\text { Bacteriuria in Pregnancy, Recurrent Urinary Tract Infections Prophylaxis }\end{array}$ \\
\hline $\mathbf{4}$ & $\begin{array}{l}\text { Sexually } \\
\text { Transmitted }\end{array}$ & $\begin{array}{l}\text { Infections that can be passed from one individual to another through sexual } \\
\text { Infection (STI) } \\
\text { Eg: Primary Syphilis, Late Latent Syphilis, Syphilis in Pregnancy, Syphilis in } \\
\text { HIV, Gonorrhea, Chlamydial (Non-specific urethritis/non-specific genital } \\
\text { infection), Chlamydial in pregnancy (Non-specific urethritis/non-specific genital } \\
\text { infection), Recurrent and persistent Non-gonococcal urethritis, Trichomoniasis }\end{array}$ \\
\hline $\mathbf{5}$ & $\begin{array}{l}\text { Acute } \\
\text { Gastroenteritis } \\
\text { (AGE) }\end{array}$ & $\begin{array}{l}\text { Infection that affects the stomach and intestines. } \\
\text { Eg: Helicobacter Pylori Infection, Watery Diarrhoea, Dysentery, Vomiting, } \\
\text { Abdominal pain, Infectious Diarrhoea, TravellersDiarrhoea }\end{array}$ \\
\hline $\mathbf{6}$ & Others & Other diagnosis that were not classified as above \\
\hline $\mathbf{7}$ & No diagnosis & $\begin{array}{l}\text { No diagnosis on prescription or diagnosis on prescription not related to } \\
\text { antibiotic prescribing }\end{array}$ \\
\hline
\end{tabular}

\section{Appendix B:Data Collection Form}

Antibiotic Prescribing Pattern in Primary Care Practice in Federal Territory of Kuala Lumpur and Putrajaya

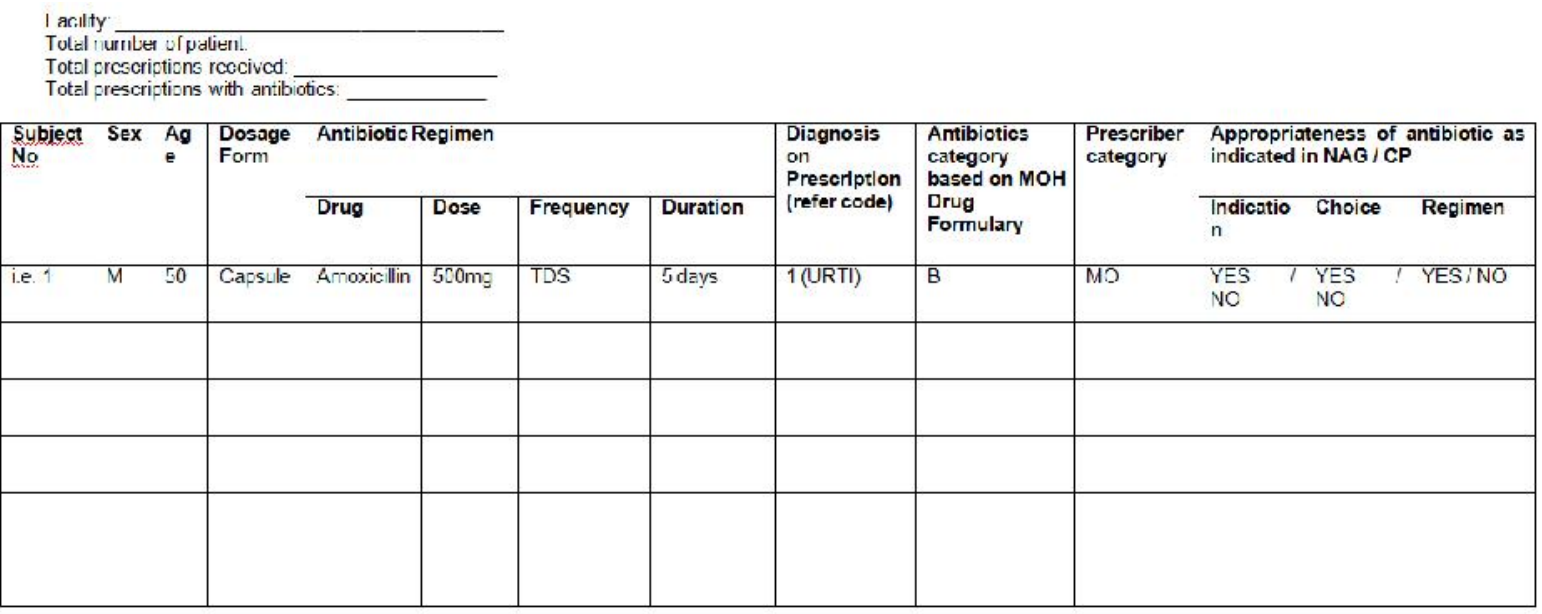

